\title{
'N PERD VAN 'N ANDER KLEUR SAS SOMERSET (1942-1986)
}

André Wessels*

This article pays homage to the SAS Somerset, the "African Queen" of the South African Navy, which was withdrawn from service on the 21nd March 1986. During her lifetime the ship rendered valuable service in aid of other ships and in harbour protection.

\begin{abstract}
Naas die bekende vlootvaartuie soos byvoorbeeld duikbote, vliegdekskepe en missieldraende aanvalsvaartuie, is daar in die meeste vlote ter wêreld ander vaartuigtipes wat soms ' $n$ groot deel van hul leeftyd hawegebonde is, maar nogtans waardevolle diens ten behoewe van ander skepe of ter beskerming van hawens verrig. Sperboomvaartuie, die lelike eendjies maar waarskynlik ook van die belangrikste werkesels in enige vloot, val in hierdie kategorie, en die SAS SOMERSET, die "AFRICAN QUEEN" van die Suid-Afrikaanse Vloot," wat op 21 Maart 1986 uit diens gestel is, was so 'n vaartuig.
\end{abstract}

Sperboomvaartuie word vir 'n verskeidenheid take gebruik, byvoorbeeld vir die lê, ophaal en instandhouding van sowel oppervlak- as onderwater-sperbome en vir die lê en verwydering van meerwerk. Hulle kan ook vir bergingswerk ingespan word. Verder kan die vaartuie gebruik word om deur die lê van navigasieboeie vaarwater af te merk, byvoorbeeld in die ingang van en binne hawens. $^{2}$

Die SAS Somerset se kiel is op 15 April 1941 as Ship No. 280 in die Blyth-skeepswerf in die noordweste van Engeland gelê, en die vaartuig is op 21 Oktober 1941 as HMS Barcross te water gelaat. Die bouers was Blyth Dry Dock en die skeepsmasjinerie is deur Swan, Hunter and Wigham Richardson van Wallsend-on-Tyne verskaf. HMS Barcross is op 14 April 1942 in diens geneem, een van 72 Bar-klas sperboomvaartuie wat in die jare 1937 tot 1945 vir die Britse Vloot gebou is. Vier verdere eenhede van die Bar-klas is in Australië vir die Australiese Vloot gebou. ${ }^{3}$

Die HMS Barcross se hoofbesonderhede was as volg: standaardverplasing 742 metrieke ton, volvragverplasing 975 metrieke ton, totale lengte $59,9 \mathrm{~m}$, dwarste $10,4 \mathrm{~m}$ en diepgang 3,5 m. Die vaartuig het een as en 'n 850 perdekrag driesilinderenjin gehad wat dit teen nege knope ter see kon laat vaar. Die ontwerpte topsnelheid was 11,75 knope. Aanvanklik was die Barcross steenkoolbrandend, maar sy enjins is later na oliebranding verander, en hy kon toe 189 metrieke ton oliebrandstof inskeep, in stede van die 217 metrieke ton steenkool van vroeër. Die vaartuig kon tot 'n radius van ongeveer $4800 \mathrm{~km}$ werk; dit kon dus met veiligheid beskutte kuswa- ters verlaat om oor groot afstande ontplooi te word. Die bemanning het uit 32 offisiere en manskappe bestaan. Gedurende die Tweede Wêreldoorlog het die vaartuig een drieduim-lugafweerkanon as bewapening gehad, maar dit is in vredestyd verwyder. ${ }^{4}$ Kort na sy indiensneming is die HMS Barcross (onder die bevel van lt V. Sutherland) en sy susterskip, HMS Barbrake, na Suid-Afrika gestuur om die sperboomdraer HMS Fernmoor te Saldanhabaai met sperboomlegging en -instandhouding behulpsaam te wees. Die twee Bar-klas vaartuie was nie lank in Suid-Afrikaanse waters nie, of hulle is na die Suid-Afrikaanse Seemag, soos die Suid-Afrikaanse Vloot destyds bekend gestaan het, oorgeplaas. Hoewel die "HMS" voor die naam van die skepe na "HMSAS" ("His Majesty's South African Ship" oftewel "Sy Majesteit se Suid-Afrikaanse Skip") verander is, het die vaartuie hul oorspronklike name behou. ${ }^{5}$

Die Barcross het tot aan die einde van die Tweede Wêreldoorlog in Suid-Afrikaanse waters diens gedoen, maar die Barbrake het die eer te beurt geval om die eerste Suid-Afrikaanse skip te word om na die Britse Vloot in die Oos-Indiese gebied, waar die stryd teen Japan nog tot 14 Augustus 1945 voortgeduur het, afgedeel te word. Dié vaartuig het op 3 Februarie vanuit Simonstad na Trincomalee in Ceylon (die huidige Sri Lanka) vertrek, en was onder meer behulpsaam by die lê van 'n ondersese pypleiding by Chittagong in wat vandag Bangladesh is. Eers op 12 Januarie 1946 was dit terug in Simonstad. ${ }^{6}$ 
In die jare na afloop van die Tweede Wêreldoorlog was Simonstad nog 'n Britse vlootbasis en het die Suid-Afrikaanse Seemag sy basis te Salisbury-eiland in Durban gehad. In die laat veertiger en in die vyftigerjare het die Suid-Afrikaanse Vloot geleidelik gegroei en is naas die drie Loch-klas fregatte wat reeds in 1944 en 1945 bekom is ook nog een groter fregat, twee torpedojaers, 'n korvet (wat plaaslik in 'n hidrografiese opmetingskip omskep is), twee diepsee-mynveërs, tien kusmynveërs en vyf seeweerbote aangekoop. Die meeste van hierdie vaartuie is ooreenkomstig die Simonstadse Ooreenkoms (1955) bekom, en op 1 April 1957 het Brittanje die Simonstad-vlootbasis aan SuidAfrika oorgedra. ${ }^{7}$

In 1951 is die Barcross tot Somerset en die Barbrake tot Fleur hernoem. Fleur was die naam van 'n perd wat genl Christiaan de Wet gedurende die Anglo-Boereoorlog gebruik het en Somerset die naam van 'n perd wat aan Dick King behoort het. Richard Philip (Dick) King (28.11.1813-10.11.1871) het as kind saam met die 1820-Setlaars na Suid-Afrika gekom en hom met verloop van tyd in Natal gaan vestig. Toe die Voortrekkers in Mei 1842 die klein Britse mag onder bevel van kapt. T.C. Smith in Port Natal (Durban) beleër het, het Dick King aangebied om hulp te gaan ontbied. In die merkwaardige tyd van tien dae, sewe dae minder as wat dit gewoonlik geneem het, het King Grahamstad bereik, ' $\mathrm{n}$ afstand van ongeveer $960 \mathrm{~km}$. Tydens die tog was Somerset een van die perde wat hy gebruik het, en dié perd het trouens nog lank daarna in sy besit gebly. Die Britte het versterkings na Port Natal gestuur en op 26 Junie 1842 is die beleërde garnisoen ontset. ${ }^{8}$ Die seeperdjie op die Somerset se skeepswapen bevestig bo alle twyfel dat hierdie 'n perd van 'n ander kleur is!

Terwyl die rol van 'n vloot se gevegsvaartuie in vredestyd tot patrolliewerk, opleidingsvaarte, maneuvers en vlagvertoonreise beperk word, gaan sperboomvaartuie se sleurwerk voort; trouens, dit kan selfs toeneem, want die vaartuie se hulp word soms ook tydens rampe en vir ander take buite vlootverband benodig. Die Somerset was in hierdie verband geen uitsondering nie. As die Barcross moes dit reeds in 1946 en 1947 nuttelose ongebruikte ammunisie in die omgewing van Kaapstad en Port Elizabeth in die oop see gooi. Toe die HMSAS Skilpad, 'n mynlêer van 941 metrieke ton, tydens 'n storm op 22 Julie 1953 by sy aanlêplek in Durban gesink het, is die Somerset se hulp ingeroep, en

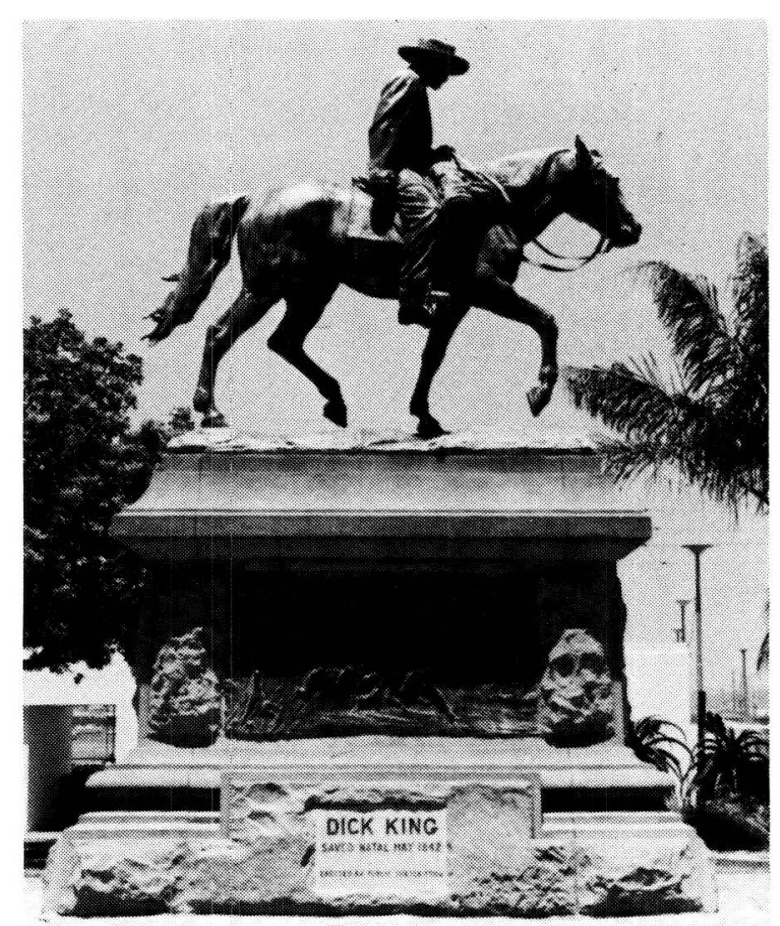

Standbeeld van Dick King op sy perd Somerset in Durban

het dit sy mede-vlootvaartuig weer op 19 November 1953 vlot gemaak. ${ }^{9}$

In 1955 het die Somerset die wrakke van drie Harvard-opleidingsvliegtuie van die Suid-Afrikaanse Lugmag geberg. Twee van die vliegtuie het oor Tafelbaai in die lug gebots en in die see gestort en die ander een het in die omgewing van Bokpunt, ongeveer $40 \mathrm{~km}$ noord van Kaapstad, in die see beland. In 1959 het die Somerset 'n oliepypleiding te Mosselbaai gelê wat 'n olie-eindpunt langs die kus met die land verbind het, en in 1961 het die vaartuig die SAS \& $\mathrm{H}$-sleepboot Schermbrucker weer vlot gemaak nadat laasgenoemde in die hawe van Oos-Londen gesink het. ${ }^{10}$ In 1968 het die "African Queen" die kabelskip John W. MacKay in die omgewing van Melkbosstrand bygestaan in die ophaal en herstel van die nuutgelegde telefoonkabel tussen Suid-Afrika en Europa. Die daaropvolgende jaar het die Somerset eers ' $n$ vaartuig genaamd Wager // in Saldanhabaai vlot gemaak en daarna ook 'n drywende hyskraan wat in die hawe van Port Elizabeth gesink het. ${ }^{11}$

Dit het selde gebeur dat die SAS Somerset nie sy opdragte suksesvol kon uitvoer nie. Een so 'n geval was egter toe sy pogings om die skip Oriental Pioneer te berg deur onder meer swak weersomstandighede gefnuik is. In 1981, op byna veertigjarige leeftyd, het dit egter daarin geslaag om die vistreiler Aldebaran weer vlot te 
maak, nadat dié vaartuig reeds bykans twee en 'n half jaar op die bodem van die Port Elizabethse hawe gelê het. In 1983 het die Somerset in Salamanderbaai aan die Kaapse Weskus twee walvisjagters en 'n trekskuit geberg. Dieselfde jaar is sy na Gansbaai gestuur om te help met die bou van die nuwe vissershawe. Hierdie werk het die lê van aanlêblokke van 24x24 m ingesluit. $^{12}$

Bogenoemde hoogtepunte uit die loopbaan van die SAS Somerset moet egter nie afbreuk doen aan sy meer alledaagse werk nie: die vervanging van swaar meerwerk, die ophaal en lê van boeie en teikens, die verlening van bystand tydens duiker-opleiding en die herwinning van torpedo's. Soms het dit ook bystand verleen wanneer van die Vloot se drie Daphne-klas duikbote met duikoefeninge in vlak water besig was. ${ }^{13}$ Vanaf einde 1965 was die Somerset boonop die enigste sperboomvaartuig in die Vloot, want op 8 Oktober 1965 is sy susterskip, SAS Fleur, wat tekens van slytasie begin toon het en aan diens onttrek is, in Valsbaai gekelder. ${ }^{14}$ Met verloop van tyd het die Somerset se bemanning uit al hoe meer bruin matrose bestaan. 'n Vloottak van die Suid-Afrikaanse Kaapse Korps is naamlik in 1966 op die been gebring met die oog daarop om die mannekragtekort in die Vloot die hoof te bied. ${ }^{15}$

$\mathrm{Na}$ 'n vol en interessante loopbaan van byna 44 jaar is die SAS Somerset op 21 Maart 1986 aan diens onttrek. Dit was op daardie stadium die laaste oorblywende skip uit die Tweede Wêreldoorlog, en gevolglik ook die oudste skip, in die Suid-Afrikaanse Vloot. ${ }^{16}$ Dit het boonop langer as enige ander skip aktiewe diens in die Vloot verrig, iets waarvan sy $830 \mathrm{~m}$ lange uitdiensnemingswimpel getuig het. ${ }^{17}$

Ses van die 72 Bar-klas vaartuie wat in Brittanje gebou is, het hul weg na ander vlote gevind. Drie is aan Turkye verkoop, twee is aan SuidAfrika oorgedra en een het in Rooi Chinese hande beland. Tans (1987) is slegs twee van die oorspronklike 76 Bar-klas sperboomvaartuie nog in vlootdiens: die oudste Bar-klas vaartuig, HMS Barbarian, wat op 21 Oktober 1937 te water gelaat is, is op 27 Februarie 1946 aan die Turkse Vloot verkoop en staan as die $A G 1$ bekend, terwyl die HMS Barlight, wat op 10 September 1938 te water gelaat is, onder 'n onbekende naam in diens van die Rooi Chinese Vloot is, ${ }^{18}$ hoewel dit waarskynlik nie meer as sperboomvaartuig nie maar as diensvaartuig gebruik word. ${ }^{19}$
In die tydperk 1942 tot 1986 het die SAS Somerset feitlik al die belangrikste gebeure in die geskiedenis van die Suid-Afrikaanse Vloot "beleef": die laaste jare van die Tweede Wêreldoorlog toe die Suid-Afrikaanse Seemag sy optimum sterkte bereik het; die na-oorlogse rasionalisasie; die daaropvolgende geleidelike ontwikkeling en opbou van 'n nuwe vloot; die toenemende internasionale isolasie van Suid-Afrika, ook op maritieme gebied; en deels as gevolg van laasgenoemde, die hernieude rasionalisasie van die Vloot in die tagtigerjare, sodat die klem tans val op die beskerming van die Suid-Afrikaanse hawens en kuswaters. ${ }^{20}$

In 1969 het die naam Fleur in die Vloot herleef met die indiensstelling van die eerste Suid-Afrikaans vervaardigde vlootvaartuig van meer as 100 ton: 'n gekombineerde torpedo-herwinningsvaartuig en duiker-ondersteuningsvaartuig met 'n standaardverplasing van 224 metrieke ton. ${ }^{21}$ Hopelik sal die naam Somerset ook weer aandag in die Suid-Afrikaanse Vloot herleef, verkieslik gekoppel aan 'n nuwe en ultra-moderne sperboomvaartuig.

* André Wessels, M.A.,D.Phil., is 'n lektor verbonde aan die Departement Geskiedenis, Universiteit van die Oranje-Vrystaat.

\section{Voetnote}

1. "The African Queen' retires", Vlootnuus 5(4), 1986 (hierna verwys as Vlootnuus), p. 3.

2. A.K. du Toit, Skepe van die Suid-Afrikaanse Vloot (Kaapstad, 1976), p. 106.

3. Ibid., p. 105; Vlootnuus, p. 3; K.D. MacKintosh, "An ode to SAS Somerset", Paratus 37(8). Aug. 1986, p. 28 en J.J. Colledge, Ships of the Royal Navy. An historical index, deel 2 (Newton Abbot, 1970), pp. 35-37, 193-194, 196, 199.

4. Du Toit, pp. 106, 109 en Jane's all the world's fighting ships, 1950-51 (Londen, 1950), p. 114.

5. Vlootnuus, p. 3 en Du Toit, p. 105.

6. J.C. Goosen (samesteller), Ons vloot. Die eerste vyftig jaar (Kaapstad 1973), p. 49. Volgens Colledge, pp. 35-37, is twee Bar-klas vaartuie tydens die oorlog gekelder. Een van hulle, die Barlight, is op 19 Desember 1941 te Hong Kong deur die Britte self laat sink, die volgende jaar deur die Japannese vlot gemaak en in diens geneem, maar toe weer op 15 Junie 1944 deur die Geallieerdes te Saipan gekelder. Daarna is die vaartuig 'n tweede keer vlot gemaak en vandag (1987) doen dit steeds diens, en wel in die Rooi Chinese Vloot.

7. Wat die ontwikkeling van die Suid-Afrikaanse Vloot tydens die vyftigerjare betref, kyk A. Wessels, "Die Suid-Afrikaanse Vloot: verlede, hede en toekoms. 'n Kort kritiese evaluering", Militaria 11(3), 1981, pp. 12-13.

8. Du Toit, p. 105; R. Russel, Natal. The land and its story (Pietermaritzburg, 1911), pp. 183-190; E. Rosenthal, Schooners and skyscrapers (Kaapstad, 1963), pp. 71-73 en Suid-Afrikaanse Biografiese Woordeboek, deel II (Kaapstad, 1972), pp. 372-373. Die Vloot se Somerset het dus geen verband met lord Charles Somerset wat vanaf 1814 tot 1826 goewerneur van die Kaapkolonie was nie.

9. Vlootnuus, p. 3 en Jane's all the word's fighting ships, 1954-55 (Londen, 1954), p. 119. In die jare 1946 tot 1955 was die latere viseadml. J.C. Walters, wat vanaf 1977 tot 1980 die hoof van die SuidAfrikaanse Vloot was, die Somerset se bevelvoerende offisier.

10. MacKintosh, p. 28 en Vlootnuus, pp. 3-4.

11. Ibid., p. 4.

12. Ibid.

13. ibid.

14. Du Toit, p. 106

15. Goosen, p. 158 
16. Die voormalige diepsee-mynveër SAS Pietermaritzburg wat op 18 Junie 1943 in 'n Britse skeepswerf te water gelaat is, is ook nog in Simonstad te sien, maar dié skip is in 1976 aan diens onttrek en word sedertdien as akkommodasieskip gebruik. Jane's all the world's fighting ships, 1975-76 (Londen, 1976), p. 294 en ibid., 1977-78 (Londen, 1977), p. 404.

17. Inligting deur Vloot-Hoofkwartier verskat; Vlootnuus, p. 3, en Mackintosh. p. 28. Daar is nog nie besluit wat met die Somerset gedoen gaan word noudat dit aan diens onttrek is nie.
18. Kyk ook voetnoot 6 hierbo.

19. Jane's all the world's fighting ships, 1986-87 (Londen, 1986), pp. 114 528 en Colledge, pp. 35-37, 193-194, 196, 199. Ten minste twaalf van die Bar-klas vaartuie is aan privaat ondernemings verkoop, maar dit is nie duidelik hoeveel van dié vaartuie nog gebruik word nie.

20. Kyk Wessels, pp. 10-18.

21. Jane's all the world's fighting ships, 1971-72 (Londen, 1971), p. 285. 